\title{
Prevention of Enamel Softening by Rinsing with a Calcium Solution before Dental Erosion
}

Körner, Philipp ; Wiedemeier, Daniel B ; Attin, Thomas ; Wegehaupt, Florian Just

\begin{abstract}
Objectives: This in situ study aimed to evaluate whether rinsing with a calcium-containing solution prior to an erosive attack reduces the softening of enamel. Materials and Methods: A total of 240 bovine enamel samples with determined baseline surface microhardness (KHN) were allocated to 5 runs in which each of the 12 volunteers performed the following experiment: 4 enamel samples were inserted in a custom-made intraoral appliance and carried in the mouth (upper jaw) for $30 \mathrm{~min}$ before each volunteer either rinsed his mouth for 60 $\mathrm{s}$ with a fluoride- and stannous ion-containing dental erosion protection mouth rinse as positive control (run 1), milk (run 2), a solution prepared from a 500-mg calcium effervescent tablet dissolved in $100 \mathrm{~mL}$ (run 3) or 200 $\mathrm{mL}$ (run 4) water, or did not perform any rinsing with a test solution before the erosive attack (run 5, negative control). To simulate the erosive attack, volunteers rinsed their mouth with a commercial soft drink (Sprite Zero) for $60 \mathrm{~s}$ and afterwards with water to stop the erosive process. Finally, surface microhardness was measured again and hardness loss $(\triangle \mathrm{KHN})$ calculated. A mixed effect model was fitted to the data set to investigate whether the different runs showed differences with respect to $\triangle K H N$. Results: No significant difference in softening of enamel (mean of $\triangle \mathrm{KHN}$; lower confidence level/upper confidence level) was observed between the negative control run 5 (50.7; 60.8/40.6), run $2(50.7 ; 60.8 / 40.6)$, run 3 (38.7; 48.8/28.6) and run 4 (40.7; 50.8/30.6) (p gt; 0.05, respectively). Enamel softening in the positive control run $1(25.4 ; 35.6 / 15.3)$ was significantly lower compared to the softening in run 5 ( $\mathrm{plt}$; 0.001). No significant difference was observed between run 1 and run 3 ( $\mathrm{p}=0.09)$. Conclusion: Other than the fluoride- and stannous ion-containing dental erosion protection mouth rinse, none of the investigated calcium-containing solutions is able to significantly reduce erosion-induced softening of enamel.
\end{abstract}

DOI: https://doi.org/10.1159/000504747

Posted at the Zurich Open Repository and Archive, University of Zurich

ZORA URL: https://doi.org/10.5167/uzh-191503

Journal Article

Published Version

Originally published at:

Körner, Philipp; Wiedemeier, Daniel B; Attin, Thomas; Wegehaupt, Florian Just (2020). Prevention of Enamel Softening by Rinsing with a Calcium Solution before Dental Erosion. Caries Research, 54(2):127-133.

DOI: https://doi.org/10.1159/000504747 


\title{
Prevention of Enamel Softening by Rinsing with a Calcium Solution before Dental Erosion
}

\author{
Philipp Körner $^{\mathrm{a}}$ Daniel B. Wiedemeier ${ }^{\mathrm{b}}$ Thomas Attin $^{\mathrm{a}}$ \\ Florian Just Wegehaupt ${ }^{a}$ \\ ${ }^{a}$ Clinic of Preventive Dentistry, Periodontology and Cariology, Center for Dental Medicine, University of Zurich, \\ Zurich, Switzerland; bStatistical Services, Center for Dental Medicine, University of Zurich, Zurich, Switzerland
}

\section{Keywords}

Dental erosion · Anorexia nervosa $\cdot$ Bulimia nervosa $\cdot$ Dental erosion protection $\cdot$ Calcium solution

\begin{abstract}
Objectives: This in situ study aimed to evaluate whether rinsing with a calcium-containing solution prior to an erosive attack reduces the softening of enamel. Materials and Methods: A total of 240 bovine enamel samples with determined baseline surface microhardness (KHN) were allocated to 5 runs in which each of the 12 volunteers performed the following experiment: 4 enamel samples were inserted in a custom-made intraoral appliance and carried in the mouth (upper jaw) for 30 min before each volunteer either rinsed his mouth for $60 \mathrm{~s}$ with a fluoride- and stannous ion-containing dental erosion protection mouth rinse as positive control (run 1), milk (run 2), a solution prepared from a 500-mg calcium effervescent tablet dissolved in $100 \mathrm{~mL}$ (run 3) or 200 $\mathrm{mL}$ (run 4) water, or did not perform any rinsing with a test solution before the erosive attack (run 5 , negative control).
\end{abstract}

To simulate the erosive attack, volunteers rinsed their mouth with a commercial soft drink (Sprite Zero) for $60 \mathrm{~s}$ and afterwards with water to stop the erosive process. Finally, surface microhardness was measured again and hardness loss $(\triangle \mathrm{KHN})$ calculated. A mixed effect model was fitted to the data set to investigate whether the different runs showed differences with respect to $\triangle K H N$. Results: No significant difference in softening of enamel (mean of $\triangle \mathrm{KHN}$; lower confidence level/upper confidence level) was observed between the negative control run $5(50.7 ; 60.8 / 40.6)$, run $2(50.7$; $60.8 / 40.6)$, run $3(38.7 ; 48.8 / 28.6)$ and run $4(40.7 ; 50.8 / 30.6)$ $(p>0.05$, respectively). Enamel softening in the positive control run $1(25.4 ; 35.6 / 15.3)$ was significantly lower compared to the softening in run $5(p<0.001)$. No significant difference was observed between run 1 and run $3(p=0.09)$. Conclusion: Other than the fluoride- and stannous ion-containing dental erosion protection mouth rinse, none of the investigated calcium-containing solutions is able to significantly reduce erosion-induced softening of enamel.

(c) 2020 S. Karger AG, Basel

Philipp Körner

Department of Preventive Dentistry, Periodontology and Cariology Center for Dental Medicine, University of Zurich, Plattenstrasse 11 CH-8032 Zurich (Switzerland)

E-Mail philipp.koerner@zzm.uzh.ch 


\section{Introduction}

Due to various risk factors, people of all ages face oral acid exposure in many different ways in their everyday life. The increased prevalence of erosive tooth wear and the associated loss of dental hard tissues has increasingly come into focus of modern dentistry [Tschammler et al., 2016]. Dental erosion as the primary etiological factor for erosive tooth wear is defined as surface dissolution of dental hard tissues caused by chemical processes not involving bacteria [Larsen, 1990]. The main factors causing dental erosion are acids from either intrinsic [Bartlett and Coward, 2001] or extrinsic [Lussi et al., 2004] origin. While extrinsic acids get in contact with dental hard tissues during consumption of acid-containing foodstuff [Lussi et al., 2004], beverages [Lussi et al., 2012] or medicaments [Hellwig and Lussi, 2014], intrinsic acids (gastric juice, mainly composed of hydrochloric acid) [Hunt, 1951] get in contact with dental hard tissues during vomiting [Roberts and Tylenda, 1989] or reflux [Bartlett et al., 1996].

It is important to notice that the erosive potential not only depends on the respective $\mathrm{pH}$ value of the attacking acid. Rather the degree of saturation of the erosive agent with respect to tooth minerals (mainly calcium), determined by the $\mathrm{pH}$ but also the lack of calcium, phosphate and fluoride, can be regarded as driving force for enamel dissolution [Lussi et al., 2009]. It was found that the erosive potential of erosive drinks is reduced or even eliminated when acidic drinks are enriched with minerals, especially calcium [Attin et al., 2003, 2005; Wegehaupt et al., 2011]. Considering solutions being saturated or even supersaturated with tooth minerals (e.g., calcium) showed no erosive effect, it might be speculated that the erosive softening of dental hard tissues is reduced, when a higher content of tooth minerals (especially calcium) is present in the oral cavity during the erosive attack. Such an enrichment might be achieved by rinsing the mouth with calcium-containing solutions immediately before the attack. The thereby increased amount of calcium in the oral cavity might act as a reservoir providing minerals to the dental erosion-causing acid and resulting in an increased saturation of the acid with calcium. Thus, the loss of tooth minerals and a demineralization of dental tissue during the erosive attack could be reduced or even prevented.

This approach could be interesting for both, patients with extrinsic and in particular for patients suffering from intrinsic dental erosion caused by deliberately induced vomiting. Tooth erosion caused by frequent regurgitation of highly acidic stomach contents is a common find- ing in patients with eating disorders, e.g. anorexia nervosa and bulimia nervosa [Roberts and Tylenda, 1989]. It is described that rinsing with a remineralizing agent after an erosive attack is able to enhance the rehardening of enamel as first therapeutic step [Amaechi and Higham, 2005] but however it seems to be indicated that the prevention of dental erosion should be the first choice of intervention to avoid erosive or erosive/abrasive tooth wear from the beginning. The first and most important measure to prevent dental erosion is the reduction of the frequency of tooth contact with dental erosion-causing acids. In patients with intrinsic dental erosion caused by deliberately induced vomiting as a symptom of a psychosocial pathological disorder, it might be impossible to completely avoid or stop the dental erosion-causing processes. Especially for these patients, it seems to be an approach to inhibit or reduce the erosion-associated softening of enamel by rinsing their teeth with a calcium-containing solution just prior to the self-induced vomiting.

Therefore, the aim of the present study was to evaluate whether rinsing with a calcium-containing solution immediately prior to an erosive attack reduces the erosioninduced softening of enamel to enable a protection towards erosively induced alteration of dental hard tissue. The hypothesis was that rinsing with a calcium-containing solution prior to an erosive attack results in minor softening of enamel compared to no rinsing.

\section{Material and Methods}

\section{Sample Preparation}

Initially, 300 enamel samples were prepared from freshly extracted bovine incisors. The teeth were sectioned at the enamelcementum junction, and enamel cylinders were gained from the buccal surface of the crowns by use of a water-cooled diamond trephine mill with an inner diameter of $3 \mathrm{~mm}$. The enamel cylinders were embedded in acrylic resin (Paladur; Heraeus Kulzer, Hanau, Germany) before enamel surfaces were ground flat and polished using water-cooled carborundum paper $(1,200 ; 2,400$; 4,000 grit) (waterproof silicon carbide paper; Struers, Erkrat, Germany). Before use, baseline surface microhardness (KHN) of all samples was determined. Out of the 300 enamel samples, a total of 240 specimens with comparable microhardness were stratified and allocated into five groups representing each experimental run $(n=$ 48). The mean KHN value of each group was 308 ; within the groups the KHN values reached from 280 to 341 ( $\pm 10 \%$ deviation from mean KHN). The samples were gamma sterilized (12 kGy, $4 \mathrm{~h}$; Paul-Scherrer-Institut, Villigen, Switzerland) and stored in tap water (Zurich) until use.

\section{Study Volunteers}

Twelve volunteers ( 6 female and 6 male) were recruited to participate in this study. Exclusion criteria were: age under 18 years, 


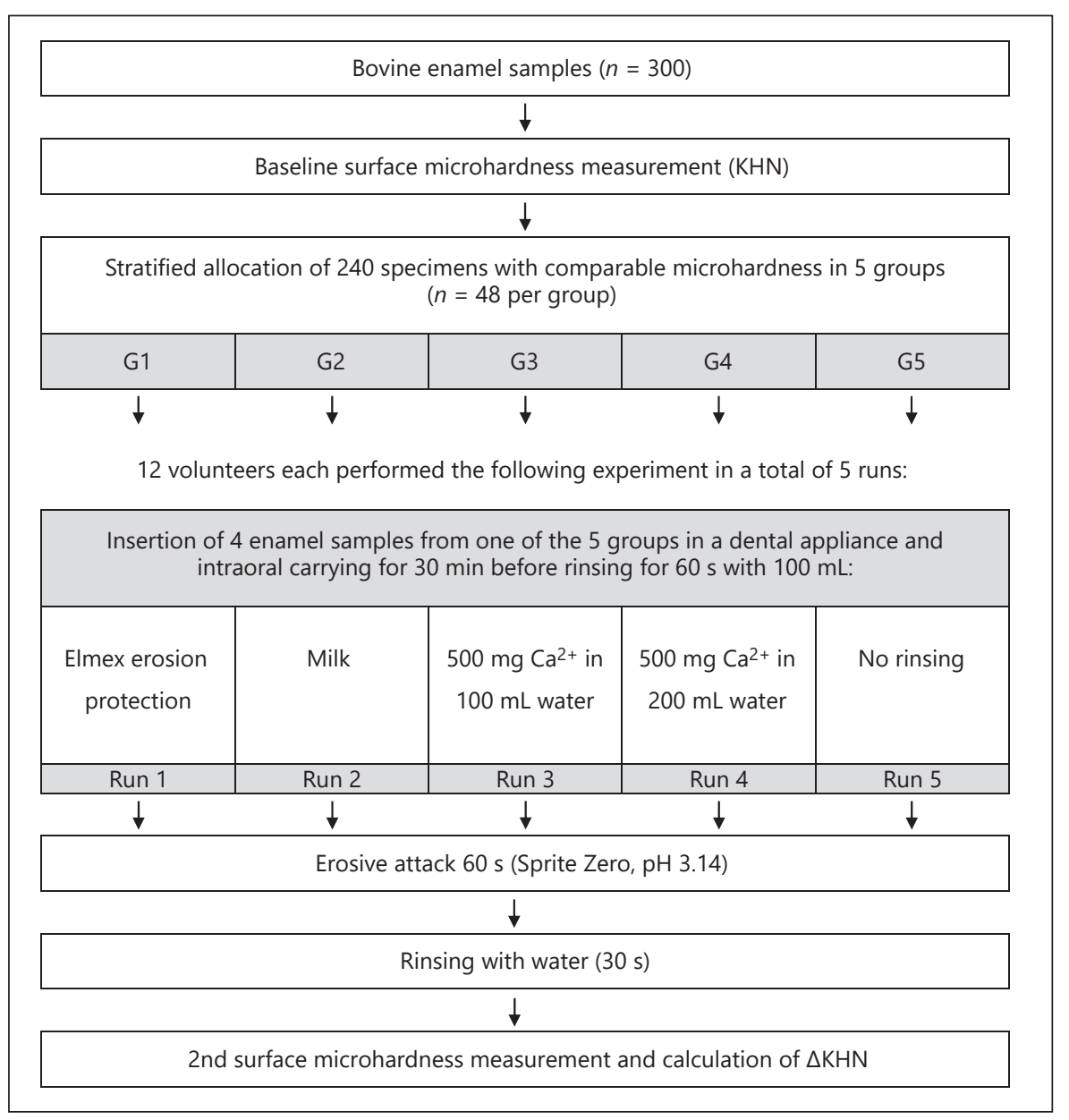

Fig. 1. Experimental design.

noncompliance, current orthodontic treatment hampering the insertion of an intraoral appliance, simultaneous participation in another clinical study, alcohol or drug addicts, heavy smokers $(>10$ cigarettes/day), patients with known allergies against products to be used in the study or patients with hyposalivation (unstimulated: $<0.25 \mathrm{~mL} / \mathrm{min}$ in $15 \mathrm{~min}$; stimulated: $<1.0 \mathrm{~mL} / \mathrm{min}$ in $5 \mathrm{~min}$ ) [Ericsson and Hardwick, 1978]. Written informed consent was obtained from each volunteer. The study was approved by the Swiss Ethics Committees on research involving humans (project ID 2017-01493) and registered with DRKS (DRKS00016757).

\section{Study Design}

In this study three different calcium-containing solutions and one fluoride- and stannous ion-containing solution as positive control were tested in 5 experimental runs for their potential to avoid or reduce dental erosion (one solution per run and one run without solution as negative control). The experimental design is illustrated in Figure 1.

For each volunteer, a custom-made intraoral appliance was fabricated, able to carry four enamel samples in the area buccal of the left and right maxillary second premolar and first molar. Each volunteer performed 5 experimental runs (one run per test solution or negative control). The sequence of runs was randomly assigned for each volunteer. Between each experimental run, a washout phase of 7 days was performed. Each volunteer started using a fluoridated toothpaste (Elmex caries protection; GABA, Therwil, Switzerland) 7 days before the experimental run and was asked not to eat or drink $2 \mathrm{~h}$ before and during the experiment. Directly before each experimental run, 4 enamel samples of the respective test group were inserted in the intraoral appliance and carried in the volunteers' mouths. After waiting for $30 \mathrm{~min}$, the volunteers either rinsed their mouths with $30 \mathrm{~mL}$ of a fluorideand stannous ion-containing dental erosion protection mouth rinse as positive control (Elmex protection erosion, $500 \mathrm{ppm} \mathrm{F}^{-}$, 800 ppm Sn ${ }^{2+}$, pH 4.5; GABA) (run 1), 30 mL milk (Naturaplan Bio Vollmilch 3.9\% Milchfett UHT, $120 \mathrm{mg} \mathrm{Ca}^{2+} / 100 \mathrm{~mL}$; Coop, Basel, Switzerland) (run 2), $30 \mathrm{~mL}$ solution prepared from a calcium effervescent tablet containing $875 \mathrm{mg}$ calcium carbonate and $1.13 \mathrm{~g}$ calcium lactate gluconate (= total $500 \mathrm{mg}$ calcium) (Calcium Sandoz 500 mg; Sandoz Pharmaceuticals AG, Rotkreuz, Switzerland) dissolved in $100 \mathrm{~mL}$ water (run 3), $30 \mathrm{~mL}$ solution prepared from a calcium effervescent tablet dissolved in $200 \mathrm{~mL}$ water (run 4) for $1 \mathrm{~min}$, or did not perform any rinsing with a test solution before the erosive attack (run 5, negative control). Within $15 \mathrm{~s}$ after finishing this step, the volunteers consecutively rinsed their mouths twice with $50 \mathrm{~mL}$ of a commercial soft drink (Sprite Zero, pH 3.14; Coca Cola Schweiz GmbH, Brüttisellen, Switzerland) for $30 \mathrm{~s}$ each to simulate an erosive attack (total erosive 
Fig. 2. Boxplot of enamel softening $(\triangle \mathrm{KHN})$ for the different applications. The lower the softening, the better the respective products prevent the erosion-induced softening. The horizontal line in the box represents the median value, the box represents the 25 th and 75 th percentiles, and whiskers represent the 5th and 95th percentiles. Not significantly different values are marked with the same superscript capital letters.

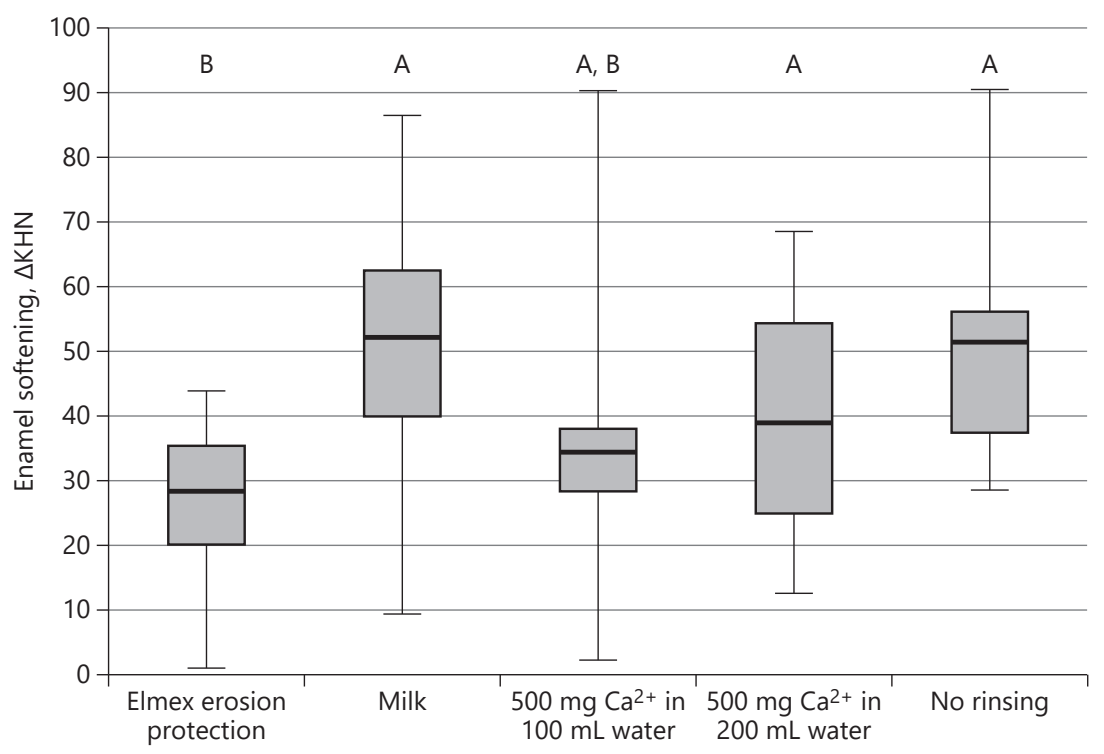

time $=60 \mathrm{~s}$ ). To stop the erosive process, the volunteers immediately rinsed their mouths with $30 \mathrm{~mL}$ tap water. After removing the samples from the appliances, the surface microhardness was determined again. Due to obvious differences in color, taste and consistency of the solutions, the study could not be performed blinded for volunteers and investigator, but still was blinded during microhardness measurement.

\section{Surface Microhardness Measurement}

The surface microhardness (KHN) of the enamel samples was determined twice: for stratified allocation (baseline) and after completion of the experimental run (final). For each measurement, 5 indentations (load weight $50 \mathrm{~g}$, indentation time $20 \mathrm{~s}$ ) were made on the enamel surface of the samples with a Knoop hardnessmeasuring device (High Quality Hardness Tester; Buehler, Düsseldorf, Germany), and the mean surface microhardness per sample was calculated. The distance between the indentations was adjusted to a minimum $50 \mu \mathrm{m}$ from each other. The microhardness measurement was performed by a blinded coworker who did not know how the respective samples had been treated. The surface hardness loss $\Delta \mathrm{KHN}$, as a measure of enamel softening and demineralization, was calculated for each sample by subtracting the final hardness from the baseline microhardness of the respective sample. The lower the mean $\triangle \mathrm{KHN}$ was, the less the samples were softened and the better the respective product hampered the erosion-induced softening.

\section{Statistical Analysis}

A mixed-linear model was fitted to the data set with $\triangle \mathrm{KHN}$ as target variable, run as explanatory variable, initial hardness as covariable (to adjust for differences in the initial hardness of the samples) and volunteer as random effect (to account for the repeated measures design). After carefully checking the model assumptions, marginal means of $\triangle \mathrm{KHN}$ per run were calculated and compared pairwise ( $p$ value was Tukey adjusted for multiple comparisons). The level of significance was set to $\alpha=0.05$. All statistical analyses were computed with the software R [R Core Team, 2015], including the packages lmerTest [Kuznetsova et al., 2016] and emmeans [Lenth, 2018].

\section{Results}

Softening (mean of $\triangle \mathrm{KHN}$; lower confidence level/upper confidence level) of the enamel samples due to erosive attack was not significantly different in run 5 (no rinsing; negative control; 50.7; 60.8/40.6), run 2 (rinse with milk; $50.7 ; 60.8 / 40.6$ ), run 3 (rinse with $500 \mathrm{mg}$ calcium effervescent tablet dissolved in $100 \mathrm{~mL}$ water; $38.7 ; 48.8 / 28.6)$ and run 4 (rinse with $500 \mathrm{mg}$ calcium effervescent tablet dissolved in $200 \mathrm{~mL}$ water; 40.7; 50.8/30.6) ( $p>0.05$, respectively). Only in run 1 (rinse with the fluoride- and stannous ion-containing dental erosion protection mouth rinse) could a significantly lower softening $(25.4 ; 35.6 / 15.3)$ of enamel due to the erosive attack compared to softening in the negative control run 5 (no rinsing) be observed ( $p<$ 0.001 ). No significant difference in softening of enamel was observed between run 1 (rinse with the fluoride- and stannous ion-containing dental erosion protection mouth rinse) and run 3 (rinse with $500 \mathrm{mg}$ calcium effervescent tablet dissolved in $100 \mathrm{~mL}$ water) $(p=0.09)$. Figure 2 illustrates a boxplot of enamel softening in the different runs. 


\section{Discussion}

The present study aimed to analyze whether rinsing with a calcium-containing solution prior to an erosive attack reduces the resulting softening of enamel and thus provides protection against dental erosion. It was found that rinsing with a fluoride- and stannous ioncontaining dental erosion protection mouth rinse can significantly reduce the erosion-induced softening of enamel. Nevertheless, the hypothesis of the present study had to be rejected as no significant protective effect was observed for solutions with a 500-mg calcium effervescent tablet (dissolved in 100 or $200 \mathrm{~mL}$ water) and for milk.

In this study, enamel specimens were prepared from bovine incisors. Bovine teeth have been used in multiple studies investigating erosive loss of dental hard tissues and can be regarded as suitable substitute for human enamel [Attin et al., 2007]. Microhardness measurement is a common method to assess changes in surface hardness of erosively altered dental hard tissues [Attin and Wegehaupt, 2014]. Using this method, surface weakening and the associated dissolution of enamel can reliably be quantified without destroying the surface and thus allowing for repetitive measurement.

Aiming to exclude interfering external influences and to create equal conditions, all study volunteers started using the same fluoridated standard toothpaste 7 days before the experimental run, were asked not to eat or drink within $2 \mathrm{~h}$ before performing the respective run and performed a washout phase of 7 days between the runs. Besides, specimens were inserted $30 \mathrm{~min}$ in advance to adapt individual intraoral conditions and enable pellicle acquisition which has been reported to have a modifying and protective effect on dental erosion even after a short time of adherence [Hannig and Hannig, 2014]. The erosive attacks were simulated using a commercial soft drink (Sprite Zero, $\mathrm{pH}$ 3.14) [Reddy et al., 2016] which was shown to have a considerable erosive potential [Pancote et al., 2014; Castilho et al., 2015; Steiger-Ronay et al., 2018]. Accordingly, the mean $\mathrm{pH}$ value of gastric acid was specified at 2.92 in a study by Bartlett and Coward [2001]. In another study by Milosevic and Dawson [1996], the average $\mathrm{pH}$ of gastric contents of bulimic patients was about 3.8. The overall duration of $60 \mathrm{~s}$ for each erosive attack aimed to simulate realistic in situ conditions (rapid consumption of $100 \mathrm{~mL}$ soft drink or acid contact during vomiting). To avoid acid dissociation, the intraoral Sprite Zero depot was refreshed after $30 \mathrm{~s}$. Subsequent to the erosive at-

Rinsing with a Calcium Solution before Dental Erosion tack, participants rinsed their mouths with water to stop the erosive process and enable comparable results. The acid-induced loss of microhardness within this experimental design was tested and verified in an internal pilot investigation.

A limiting factor might be that due to obvious differences in color, taste and consistency of the solutions, the study could not be performed blinded for volunteers and investigator. Nevertheless, microhardness measurement was performed blinded to avoid bias of the results. Another limiting factor might be that citric acid, which is contained in free sale commercial soft drinks, was used instead of hydrochloric acid (gastric juice) which has to be attributed to ethical restrictions. However, citric acid was shown to be more erosive than $\mathrm{HCl}$ [Hannig et al., 2005] and can be regarded as capable substitute in testing protective measures. It can be assumed that a protective measure which showed prevention under severer conditions does also show this effect under less severe conditions. The calcium content of saliva and/or pellicle and further characteristics of the calcium solution, such as dissolution of calcium, viscosity and temperature were not assessed in this study, but might still have an influence on the results and should be addressed in further studies. For example, the high deviation in the calcium groups when compared to positive and negative control might be attributed to the interindividually differing calcium content of saliva and/ or pellicle leading to a minor or major total amount of calcium in the oral cavity while rinsing with one of the respective solutions.

Prior to the study, it was speculated that the erosive softening of dental hard tissues might be reduced, in case that a higher content of tooth minerals (especially calcium) is present in the oral cavity during the erosive attack enabling an increased saturation of the acid. However, there are no comparable studies investigating this assumption so that no reference for the required amount of calcium was given. The findings of the present study show that enamel softening was reduced in case the volunteers rinsed their mouths with a fluoride- and stannous ioncontaining dental erosion protection mouth rinse or a calcium effervescent tablet dissolved in $100 \mathrm{~mL}$ water prior to the erosive attack. Nevertheless, the reduction in the calcium effervescent tablet dissolved in $100 \mathrm{~mL}$ water group was not statistically significant. To interpret the results, it might be helpful to compare the findings with the chemical characteristics of the different solutions used in this study, in particular with respect to the calcium concentration. The comparison of the same kind of calcium 
effervescent tablet (500 $\mathrm{mg} \mathrm{Ca}^{2+}$ ) dissolved either in 100 $\mathrm{mL}\left(\triangleq 150 \mathrm{mg} \mathrm{Ca}^{2+}\right.$ per rinse of $30 \mathrm{~mL}$ ) or in $200 \mathrm{~mL}(\triangleq 75$ $\mathrm{mg} \mathrm{Ca}{ }^{2+}$ per rinse of $30 \mathrm{~mL}$ ) water indicates that an increased concentration of calcium correlates with reduced dental erosion. Likewise, Wegehaupt et al. [2016] observed that effervescent tablets with higher calcium concentration induce less enamel loss compared to those with similar $\mathrm{pH}$, but lower calcium concentration. The overall highest amount of calcium in this study $(500 \mathrm{mg}$ in $100 \mathrm{~mL}$ ) might have provided the greatest reservoir of minerals in the oral cavity, thus leading to an increased saturation of the attacking acid compared to the other calcium groups. Due to the promising tendency in this group, further studies are planned to investigate the effect of rinsing with even higher concentrations of calcium as it could be provided in $1,000 \mathrm{mg}$ effervescent tablets. The poor performance of milk in this study indicates that the contained amount of calcium $\left(\bumpeq 36 \mathrm{mg} \mathrm{Ca}^{2+}\right.$ per rinse of $30 \mathrm{~mL}$ ) might be insufficient in order to enable a reduction of enamel softening which is in accordance with another study describing milk as not effective at reducing erosive enamel and dentine loss significantly [Wiegand and Attin, 2014]. It might be assumed that, due to a high fat and protein content, milk might form a protective deposition on enamel possibly limiting the interaction of acid with the enamel surface [Magalhães et al., 2014]. However, the results in this study deny this assumption which might be attributed to active acid rinsing leading to a rapid dissolution of a protective deposition.

The overall highest surface protection was observed for the stannous-chloride/fluoride-containing mouth rinse. Numerous other studies describe equally pronounced and effective antierosive properties for this product [Ganss et al., 2010; Yu et al., 2010; Pini et al., 2016; Attin et al., 2017]. Nevertheless, the antierosive effect might be less attributed to an increased saturation of the attacking acid. Rather the two fluoride compounds $(\mathrm{NaF}$ and $\mathrm{AmF})$ and stannous ion, which is a potent reactant with hydroxyapatite, might have interacted with the outer enamel, reducing its solubility and building a glaze layer of $\mathrm{Sn}_{2} \mathrm{OHPO}_{4}$, $\mathrm{Sn}_{3} \mathrm{~F}_{3} \mathrm{PO}_{4}, \mathrm{Ca}\left(\mathrm{SnF}_{3}\right) 2$ and $\mathrm{CaF}_{2}$, thus enabling the formation of a resistant and protective surface coating against the attacking acid even after 60-s single application [Yu et al., 2010]. It remains to be answered whether the dental erosion reducing effect can be attributed rather to the fluoride or stannous ion component or the combination of both agents. However, the approach seems to be possible and might be an interesting opportunity in the sense of primary prophylaxis of erosive tooth wear especially for vomiting patients. The likelihood of one to use a rinse be- fore dental erosion appears to be a matter of personal responsibility on the one hand, but also a matter of feasibility (e.g., in case of extrinsic acid contact) and could be assessed in further investigations.

\section{Conclusion}

Within the limitations of the present study, it can be concluded that rinsing with a fluoride- and stannous ioncontaining dental erosion protection mouth rinse before an erosive attack can reduce but not totally hamper the erosion-induced softening of enamel. None of the investigated calcium-containing solutions is able to significantly reduce erosion-induced softening of enamel. As an obvious tendency towards an increased protective effect with increased calcium concentration could be observed, it could be worth following up with even higher concentrations. Therefore, further studies are needed to verify whether higher concentrated calcium solutions (e.g., $1,000 \mathrm{mg} \mathrm{Ca}{ }^{2+}$ tablet dissolved in $100 \mathrm{~mL}$ water) might be able to significantly reduce the erosion-associated enamel softening.

\section{Statement of Ethics}

Written informed consent was obtained from each volunteer. The study was approved by the Swiss Ethics Committees on research involving humans (project ID 2017-01493) and registered with DRKS (DRKS00016757).

\section{Disclosure Statement}

The authors have no conflicts of interest to declare.

\section{Funding Sources}

The project was funded by the Swiss Anorexia Nervosa Foundation.

\section{Author Contributions}

Philipp Körner: performed the clinical experiment and wrote the manuscript. Daniel B. Wiedemeier: performed statistical evaluation, proofread the manuscript. Thomas Attin: research idea, contributed substantially to discussion and writing the paper, proofread the manuscript. Florian J. Wegehaupt: research idea, hypothesis, experimental design, contributed substantially to discussion and writing the paper, proofread the manuscript. 


\section{References}

Amaechi BT, Higham SM. Dental erosion: possible approaches to prevention and control. J Dent. 2005 Mar;33(3):243-52.

Attin T, Becker K, Wiedemeier DB, Schmidlin PR, Wegehaupt FJ. Anti-erosive effect of a self-assembling peptide gel. Swiss Dent J. 2017;127(10):857-64.

Attin T, Meyer K, Hellwig E, Buchalla W, Lennon AM. Effect of mineral supplements to citric acid on enamel erosion. Arch Oral Biol. 2003 Nov;48(11):753-9.

Attin T, Wegehaupt F, Gries D, Wiegand A. The potential of deciduous and permanent bovine enamel as substitute for deciduous and permanent human enamel: erosion-abrasion experiments. J Dent. 2007 Oct;35(10):773-7.

Attin T, Wegehaupt FJ. Methods for assessment of dental erosion. Monogr Oral Sci. 2014;25: 123-42.

Attin T, Weiss K, Becker K, Buchalla W, Wiegand A. Impact of modified acidic soft drinks on enamel erosion. Oral Dis. 2005 Jan;11(1):712.

Bartlett DW, Coward PY. Comparison of the erosive potential of gastric juice and a carbonated drink in vitro. J Oral Rehabil. 2001 Nov; 28(11):1045-7.

Bartlett DW, Evans DF, Smith BG. The relationship between gastro-oesophageal reflux disease and dental erosion. J Oral Rehabil. 1996 May;23(5):289-97.

Castilho AR, Salomão PM, Buzalaf MA, Magalhães AC. Protective effect of experimental mouthrinses containing $\mathrm{NaF}$ and TiF4 on dentin erosive loss in vitro. J Appl Oral Sci. 2015 Oct;23(5):486-90.

Ericsson Y, Hardwick L. Individual diagnosis, prognosis and counselling for caries prevention. Caries Res. 1978;12 Suppl:194-202. https://doi.org/10.1159/000402436.

Ganss C, Neutard L, von Hinckeldey J, Klimek J, Schlueter N. Efficacy of a tin/fluoride rinse: a randomized in situ trial on erosion. J Dent Res. 2010 Nov;89(11):1214-8.
Hannig C, Hamkens A, Becker K, Attin R, Attin T. Erosive effects of different acids on bovine enamel: release of calcium and phosphate in vitro. Arch Oral Biol. 2005 Jun;50(6):541-52.

Hannig M, Hannig C. The pellicle and erosion. Monogr Oral Sci. 2014;25:206-14.

Hellwig E, Lussi A. Oral hygiene products, medications and drugs - hidden aetiological factors for dental erosion. Monogr Oral Sci. 2014;25:155-62.

Hunt JN. The composition of gastric juice. Physiol. 1951 May;113(4):419-24.

Kuznetsova A, Brockhoff PB, Christensen RH. lmerTest: tests in linear mixed effects models. $\mathrm{R}$ package version 2.0-33. 2016. Available from: https://CRAN.Rproject.org/package $=$ lmerTest

Larsen MJ. Chemical events during tooth dissolution. J Dent Res. 1990 Feb;69(Spec No):57580.

Lenth R. Emmeans: estimated marginal means, aka least-squares means. $\mathrm{R}$ package version 1.2.3. 2018. Available from: https://CRAN.Rproject.org/package $=$ emmeans

Lussi A, Hellwig E, Ganss C, Jaeggi T. Buonocore memorial lecture. Dental erosion. Oper Dent. 2009 May-Jun;34(3):251-62.

Lussi A, Jaeggi T, Zero D. The role of diet in the aetiology of dental erosion. Caries Res. 2004; 38 Suppl: 134-44. https://doi.org/10.1159/ 000074360 .

Lussi A, Megert B, Shellis RP, Wang X. Analysis of the erosive effect of different dietary substances and medications. Br J Nutr. 2012 Jan; 107(2):252-62.

Magalhães AC, Levy FM, Souza BM, Cardoso CA, Cassiano LP, Pessan JP, et al. Inhibition of tooth erosion by milk containing different fluoride concentrations: an in vitro study. J Dent. 2014 Apr;42(4):498-502.

Milosevic A, Dawson LJ. Salivary factors in vomiting bulimics with and without pathological tooth wear. Caries Res. 1996;30(5):361-6.

Pancote LP, Manarelli MM, Danelon M, Delbem AC. Effect of fluoride gels supplemented with sodium trimetaphosphate on enamel erosion and abrasion: in vitro study. Arch Oral Biol. 2014 Mar;59(3):336-40.
Pini NI, Lima DA, Lovadino JR, Ganss C, Schlueter N. In vitro Efficacy of Experimental Chitosan-Containing Solutions as Anti-Erosive Agents in Enamel. Caries Res. 2016;50(3): 337-45.

R Core Team. R: a language and environment for statistical computing. R Foundation for Statistical Computing. 2015. Available from: https://www.R-project.org/

Reddy A, Norris DF, Momeni SS, Waldo B, Ruby JD. The $\mathrm{pH}$ of beverages in the United States. J Am Dent Assoc. 2016 Apr;147(4):255-63.

Roberts MW, Tylenda CA. Dental aspects of anorexia and bulimia nervosa. Pediatrician. 1989;16(3-4):178-84.

Steiger-Ronay V, Steingruber A, Becker K, AykutYetkiner A, Wiedemeier DB, Attin T. Temperature-dependent erosivity of drinks in a model simulating oral fluid dynamics. J Dent. 2018 Mar;70:118-23.

Tschammler C, Müller-Pflanz C, Attin T, Müller $\mathrm{J}$, Wiegand A. Prevalence and risk factors of erosive tooth wear in 3-6 year old German kindergarten children - a comparison between 2004/05 and 2014/15. J Dent. 2016 Sep; 52:45-9.

Wegehaupt F, Günthart N, Sener B, Attin T. Prevention of erosive/abrasive enamel wear due to orange juice modified with dietary supplements. Oral Dis. 2011 Jul;17(5):508-14.

Wegehaupt FJ, Lunghi N, Hogger VM, Attin T. Erosive potential of vitamin and vitamin + mineral effervescent tablets. Swiss Dent J. 2016;126(5):457-65.

Wiegand A, Attin T. Randomised in situ trial on the effect of milk and CPP-ACP on dental erosion. J Dent. 2014 Sep;42(9):1210-5.

Yu H, Wegehaupt FJ, Zaruba M, Becker K, Roos M, Attin T, et al. Erosion-inhibiting potential of a stannous chloride-containing fluoride solution under acid flow conditions in vitro. Arch Oral Biol. 2010 Sep;55(9):702-5. 